DOI: 10.12731/2658-6649-2020-12-5-150-164

УДК 616.12.127: 616-056.52

\title{
ОСОБЕННОСТИ ВАРИАНТОВ РЕМОДЕЛИРОВАНИЯ ЛЕВОГО ЖЕЛУДОЧКА У МУЖЧИН МИГРАНТОВ КРАЙНЕГО СЕВЕРА С АРТЕРИАЛЬНОЙ ГИПЕРТОНИЕЙ, РАЗЛИЧНЫХ КОНСТИТУЦИОНАЛЬНЫХ ТИПОВ
}

Яскевич Р.А., Москаленко О.Л.

Цель. Изучение вариантов ремоделирования левого желудочка (ЛЖ) у мужчин, жителей Севера с артериальной гипертонией (АГ), различных конституциональных типов, переехавших на постоянное место жительства в Центральную Сибирь.

Материалы и методы. В исследовании приняло участие 172 пациента с АГ мужского пола. В основную группу вошло 86 мужчин с АГ, ранее проживавших в условиях Крайнего Севера. Использовалась стандартная методика антропометрического исследования с последующим определением конституциональных типов, а также определение типов геометрического ремоделирования ЛЖ по данным ультразвукового исследования сердия. Результаты. Данные проведенного исследования выявили конституциональные особенности частоты неблагоприятных типов ремоделирования у мужчин обследованных групп. Мигранты с АГ характеризуются высокой частотой эксиентрической гипертрофии ЛЖ при брюшном соматотипе и высокой частотой концентрической гипертрофия ЛЖ при мускульном, в то время как мужчины с АГ, постоянно проживающих в г. Красноярске, характеризуются высокой частотой конщентрической гипертрофии ЛЖ при брюшном соматотипе и высокой частотой эксиентрической гипертрофии ЛЖ при мускульном соматотипе.

Заключение. Неблагоприятные типы геометрии ЛЖ среди мигрантов Крайнего Севера чаще встречаются у лиц с конституциональными типами, характеризуюшиеся высоким содержание жировой ткани (брюшной соматотип) и мылечной ткани (мускульный соматотип).

Ключевые слова: артериальная гипертония; ремоделирование миокарда левого желудочка; соматотип; Крайний Север. 


\section{FEATURES OF LEFT VENTRICULAR REMODELING OPTIONS IN MALE MIGRANTS OF THE FAR NORTH WITH ARTERIAL HYPERTENSION, DIFFERENT CONSTITUTIONAL TYPES}

\section{Yaskevich R.A., Moskalenko O.L.}

Purpose. Study of left ventricular ( $L V)$ remodeling options in men, residents of the North with arterial hypertension $(A G)$, various constitutional types who moved to permanent residence in Central Siberia.

Materials and methods. The study involved 172 male AG patients. The main group included 86 men from the AG who had previously lived in the Far North. A standard anthropometric examination technique was used, followed by the definition of constitutional types, as well as the definition of geometric $L V$ remodeling types from cardiac ultrasound data.

Results. The data of the conducted study revealed the constitutional features of the incidence of adverse types of remodeling in men of the examined groups. Migrants with $A G$ are characterized by a high frequency of eccentric LV hypertrophy in abdominal somatotype and a high frequency of concentric LV hypertrophy in muscular, while men with AG permanently living in Krasnoyarsk are characterized by a high frequency of concentric LV hypertrophy in abdominal somatotype and a high frequency of eccentric LV hypertrophy

Conclusion. Adverse types of LV geometry among migrants of the Far North are more common in individuals with constitutional types characterized by high adipose tissue (abdominal somatotype) and muscle tissue (muscular somatotype).

Keywords: arterial hypertension; left ventricular myocardial remodeling; somatotype; Far North.

\section{Введение}

Заболевания сердечно-сосудистой системы как причина инвалидизации и летальности среди других нозологических форм занимают одно из первых мест не только во всем мире [21, 23, 25], но и в России [1, 12, $18,22]$. Между различными формами сердечно-сосудистой патологии, артериальная гипертония (АГ) привлекает всеобщее внимание, которое обусловлено её высокой популяционной частотой, негативным влиянием на состояние здоровья, работоспособность и продолжительность жизни населения $[3,18,24]$. Своевременный контроль факторов риска 
СС3 на ранней стадии заболевания, может предотвратить дальнейшее развитие патологического процесса $[4,7,12,19]$. Известно, что независимым предиктором заболеваемости и смертности от ССЗ является масса миокарда левого желудочка (ММЛЖ) [5, 6], а масса тела была признана в качестве наиболее важного детерминирующего признака ММЛЖ [19]. Считается, что независимо от наличия или отсутствия АГ, ожирение связано с увеличением ЛЖ. В связи с чем, в качестве мер по профилактики или уменьшения гипертрофии ЛЖ (ГЛЖ) было рекомендовано снижение массы тела [18]. Также установлено, что из компонентов массы тела, наиболее тесно связана с ГЛЖ её жировая [17] и мышечная составляющие [20].

В ходе проведенных ранее исследований выделен «северный» вариант АГ [13], для которого характерно сглаженность суточного профиля АД, нарушение циркадности суточного ритма, повышение метеолабильности, более жесткое течение и более раннее поражение органов-мишеней, обусловленное гипертрофией миокарда ЛЖ и трофическими изменениями сосудистой стенки $[13,24]$. Проживание человека в гипокомфортных климатогеографических условиях в сочетании с антропогенной нагрузкой приводит к более интенсивному использованию адаптационных резервов организма и как следствие, скорейшему их истощению [13]. Воздействие факторов внешней среды на организм человека может выражаться в различии антропометрических параметров населения $[15,16]$. Индивидуально-типологические особенности человека можно считать маркерами, характеризующими особенности клинических проявлений, которые могут быть использованы в прогнозе развития тех или иных заболеваний и тяжести их течения $[2,8,10,14,15]$. Имеются данные о том, что определённое внешнее строение тела человека может соответствовать не только определенному внутреннему его строению, но и анатомо-физиологическим особенностям сердца и сосудов $[8,11]$. В связи с этим большой интерес представляет изучение взаимосвязи конституциональных особенностей и вариантов ремоделирования левого желудочка у жителей Севера с АГ, различных конституциональных типов, переехавших на постоянное место жительства в Центральную Сибирь.

\section{Цель исследования}

Изучить частоту вариантов ремоделирования ЛЖ у мужчин, жителей Севера с АГ, различных конституциональных типов, переехавших на постоянное место жительства в Центральную Сибирь. 


\section{Материалы и методы}

Для изучения частоты вариантов ремоделирования ЛЖ у лиц с АГ различных типов конституции, обследовано 172 пациента мужского пола, проходивших стационарное лечение в кардиологическом отделении НИИ медицинских проблем Севера - обособленном подразделении ФИЦ КНЦ СО РАН (НИИ МПС ФИЦ КНЦ СО РАН) г. Красноярска. Основную группу составили - мужчины пришлого населения (европеоиды) с АГ, ранее проживавшие на Крайнем Севере (г. Норильск) и переехавшие на постоянное место жительства в Центральную Сибирь (г. Красноярск, г. Минусинск) (86 чел., медиана возраста - 63 [56; 69] года), группу сравнения - мужчины с АГ, постоянно проживающие в г. Красноярске (86 чел., медиана возраста - $64[58 ; 68]$ года). Сравниваемые группы по не имели различий по возрасту ( $U=15737,0 ; Z=-0,64 ; p=0,518)$. Все участвующие в обследовании пациенты давали письменное информированное согласие. Исследование проводилось в соответствии с этическими принципами проведения исследований с участием человека Хельсинской Декларации Всемирной Медицинской Ассоциации (Declaration of Helsinki), пересмотр 2013 г. и было одобрено локальным этическим комитетом НИИ МПС ФИЦ КНЦ СО РАН.

Антропометрическое исследование проводилось по общепринятым правилам антропометрических измерений. Соматотипирование проводилось по методу Бунака В. В. (1931) в модификации Чтецова В. П. с соавт. (1978) [8].

Типы геометрического ремоделирования ЛЖ определяли по классификации Ganau A. с соавт. (1992), на основе определения индекса массы миокарда ЛЖ (ИММЛЖ) и относительной толщины стенок ЛЖ (ОТСЛЖ). Гипертрофию миокарда ЛЖ диагностировали при значениях ИММЛЖ

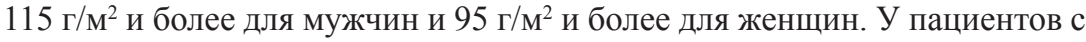
эксцентрической гипертрофией ЛЖ, концентрической гипертрофией ЛЖ и концентрическим ремоделированием ЛЖ геометрическая модель ЛЖ рассматривалась как патологическая.

Статистический анализ полученных результатов проводился с использованием программы Statistica 6.0 № EXXR202F256520FAN10 («StatSoft», США). Количественные данные представляли в виде медианы Ме и межквартильного диапазона $\left[\mathrm{C}_{25} ; \mathrm{C}_{75}\right]$, Статистическую значимость различий между группами при проверке нулевой гипотезы оценивали согласно критерию Манна-Уитни-Вилкоксона. Оценка сравнения качественных показателей проводилась с использованием критерия $\chi^{2}$ (chi-squrae) Пирсона. 
Критический уровень статистической значимости при проверке нулевой гипотезы принимали при 95\% уровне значимости $(\mathrm{p} \leq 0,05)$.

\section{Результаты и обсуждение}

На основании результатов проведенного антропометрического исследования, обследованные мигранты и жители г. Красноярска, мужского пола, были распределены по соматотипам (рис.1). Среди мужчин мигрантов, больных АГ, чаще определялся мускульный конституциональный тип $-50,0 \%$ (43 чел. из 86) ( $\mathrm{p}=0,001)$, реже наблюдались лица с брюшным типом конституции - 38,4\% (33 чел. из 86), неопределенным - 7,0\% (6 чел. из 86) и грудным - 4,7\% (4 чел. из 86) соответственно (рис. 1 ). Среди мужчин, постоянно проживающих в г. Красноярске (39 чел.) чаще встречался брюшной соматотип 47,7\% (41 чел. из 86) ( $\mathrm{p}=0,001)$, реже мускульный $41,9 \%$ (36 чел. из 86), неопределенный - 5,8\% (5 чел. из 86) и грудной $4,7 \%$ (4 чел. из 86) (рис.1) соответственно.

Полученные результаты согласуются с данными проведенных ранее исследований среди мужчин г. Красноярска с АГ $[15,16]$ а также с результатами исследований Деревянных Е.В. с соавт. (2016) [2] и Козлова Е.В. с соавт. (2019) [9], согласно которых, самую многочисленную группу среди обследованных мужчин с АГ составили представители брюшного соматотипа.

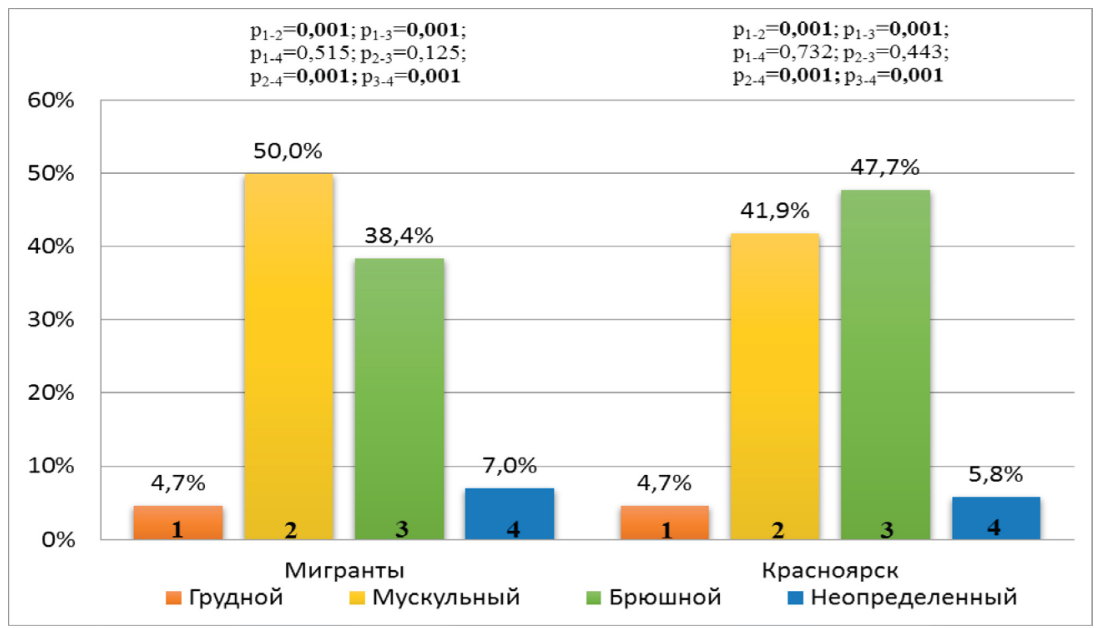

Рис. 1. Конституциональная характеристика обследуемых с АГ, мигрантов и жителей г. Красноярска. 
Установлено, что между собой обследуемые группы не имели статистически значимых различий по частоте изучаемых конституциональных типов: брюшной соматотип - 38,4\% vs $47,7 \%\left(\chi^{2}=1,52, \mathrm{df}=1, \mathrm{p}=0,218\right)$, грудной $-4,7 \%$ vs $4,7 \%\left(\chi^{2}=0,00, \mathrm{df}=1, \mathrm{p}=1,000\right)$, мускульный $50,0 \%$ vs $41,9 \%$ $\left(\chi^{2}=1,15, \mathrm{df}=1, \mathrm{p}=0,284\right)$ и неопределенный $-7,0 \%$ vs $5,8 \%\left(\chi^{2}=0,10, \mathrm{df}=1\right.$, $\mathrm{p}=0,755)$ тип конституции соответственно.

Проведен анализ уровней АД среди обследованных мужчин обеих групп с АГ, различных конституциональных типов. Отмечено, что наименьшие цифры АД среди мужчин больных АГ, обеих групп, определялись при грудном конституциональном типе, тогда как наибольшие значения АД, на уровне тенденции, отмечались среди лиц с брюшным типом конституции. Подобные тенденции были установлены ранее при обследовании мужчин, медицинских работников с АГ [2] и при изучении частоты нарушений ритма сердца у мужчин с АГ, различных соматотипов [15]. Между собой обследуемые группы мужчин не имели статистически значимых различий по уровням АД.

Исходя из полученных данных ультразвукового исследования сердца, пациенты обеих групп с АГ были разделены на группы согласно классификации Ganau A. с соавт. (1992) (рис. 2).

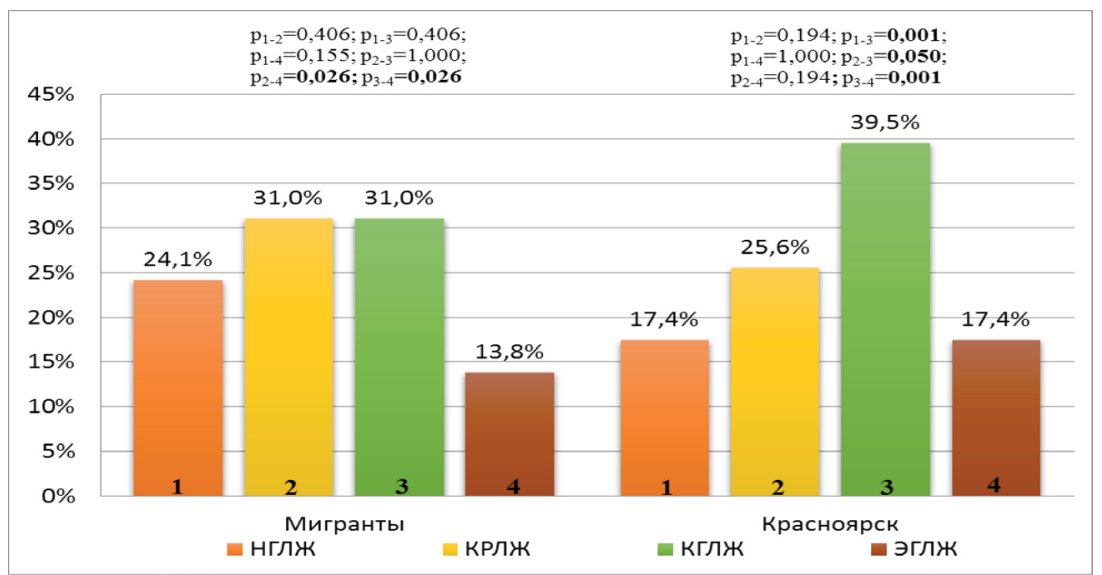

Рис. 2. Частота вариантов ремоделирования ЛЖ у обследуемых с АГ, мигрантов и жителей г Красноярска.

Примечание: НГЛЖ - нормальная геометрия ЛЖ, КРЛЖ - концентрическое ремоделирование ЛЖ, КГЛЖ - концентрическая гипертрофия ЛЖ, ЭГЛЖ - эксцентрическая гипертрофия ЛЖ. 
У 24,1\% (14 чел. из 58) мигрантов Крайнего Севера, больных АГ ИММЛЖ и геометрия ЛЖ соответствовали нормативным величинам. Около трети обследованных имели концентрическое ремоделирование ЛЖ (КРЛЖ) - 31,0\% (18 чел. из 58) и концентрическую ГЛЖ (КГЛЖ) - 31,0\% (18 чел. из 58), реже эксцентрическую ГЛЖ (ЭГЛЖ) - 13,8\% (8 чел. из 58) соответственно ( $\mathrm{p}=0,026)$.

Изучена частота вариантов ремоделирования ЛЖ у мигрантов с АГ различных соматотипов (табл.1).

Таблицуа 1.

Частота встречаемости вариантов ремоделирования левого желудочка у мигрантов Крайнего Севера с АГ, различных соматотипов

\begin{tabular}{|c|c|c|c|c|c|}
\hline \multirow{3}{*}{$\begin{array}{c}\text { Тип ремоде- } \\
\text { лирования }\end{array}$} & \multicolumn{4}{|c|}{ Соматотипы } & \multirow{3}{*}{$p$} \\
\hline & 1. Грудной & $\begin{array}{c}\text { 2. Мускуль- } \\
\text { ный }\end{array}$ & 3. Брюшной & $\begin{array}{l}\text { 4. Неопреде- } \\
\text { ленный }\end{array}$ & \\
\hline & абс. (\%) & абс. (\%) & абс. (\%) & абс. (\%) & \\
\hline $\begin{array}{l}\text { 1. Нормаль- } \\
\text { ная геоме- } \\
\text { трия ЛЖ } \\
\end{array}$ & $1(7,1 \%)$ & $8(57,1 \%)$ & $4(28,6 \%)$ & $1(7,1 \%)$ & $\begin{array}{l}\mathrm{p}_{1-2}=\mathbf{0 , 0 2 0} ; \mathrm{p}_{1-3}=0,244 ; \\
\mathrm{p}_{1-4}=0,674 ; \mathrm{p}_{2-3}=0,157 ; \\
\mathrm{p}_{2-4}=0,114 ; \mathrm{p}_{3-4}=0,562\end{array}$ \\
\hline $\begin{array}{l}\text { 2. Концен- } \\
\text { трическое } \\
\text { РЛЖ } \\
\end{array}$ & $1(5,6 \%)$ & $7(38,9 \%)$ & $9(50,0 \%)$ & $1(5,6 \%)$ & $\begin{array}{l}\mathrm{p}_{1-2}=\mathbf{0 , 0 4 0} ; \mathrm{p}_{1-3}=\mathbf{0 , 0 1 0} ; \\
\mathrm{p}_{1-4}=0,674 ; \mathrm{p}_{2-3}=0,502 ; \\
\mathrm{p}_{2-4}=0,178 ; \mathrm{p}_{3-4}=0,070\end{array}$ \\
\hline $\begin{array}{l}\text { 3. Концен- } \\
\text { трическая } \\
\text { ГЛЖ } \\
\end{array}$ & $0(0,0 \%)$ & $11(61,1 \%)$ & $6(33,3 \%)$ & $1(5,6 \%)$ & $\begin{array}{l}\mathrm{p}_{1-2}=\mathbf{0 , 0 0 1 ;} \mathrm{p}_{1-3}=\mathbf{0 , 0 1 7} ; \\
\mathrm{p}_{1-4}=0,176 ; \mathrm{p}_{2-3}=0,095 ; \\
\mathrm{p}_{2-4}=\mathbf{0 , 0 2 2} ; \mathrm{p}_{3-4}=0,269\end{array}$ \\
\hline $\begin{array}{l}\text { 4. Эксцен- } \\
\text { трическая } \\
\text { ГЛЖ } \\
\end{array}$ & $1(12,5 \%)$ & $3(37,5 \%)$ & $4(50,0 \%)$ & $0(0,0 \%)$ & $\begin{array}{l}\mathrm{p}_{1-2}=0,419 ; \mathrm{p}_{1-3}=0,244 ; \\
\mathrm{p}_{1-4}=0,439 ; \mathrm{p}_{2-3}=0,674 ; \\
\mathrm{p}_{2-4}=0,220 ; \mathrm{p}_{3-4}=0,147\end{array}$ \\
\hline$p$ & $\begin{array}{l}\mathrm{p}_{1-2}=1,000 ; \mathrm{p}_{1-3}=0,309 ; \\
\mathrm{p}_{1-4}=1,000 ; \mathrm{p}_{2-3}=0,309 ; \\
\mathrm{p}_{2-4}=1,000 ; \mathrm{p}_{3-4}=0,309\end{array}$ & $\begin{array}{l}\mathrm{p}_{1.2}=0,735 ; \mathrm{p}_{1.3}=0,317 ; \\
\mathrm{p}_{1-4}=\mathbf{0}, \mathbf{0 7 0} ; \mathrm{p}_{2.3}=0,182 ; \\
\mathrm{p}_{24}=0,137 ; \mathrm{p}_{3-4}=0,006\end{array}$ & $\begin{array}{l}\mathrm{p}_{1.2}=0,083 ; \mathrm{p}_{1.3}=0,457 ; \\
\mathrm{p}_{1-4}=1,000 ; \mathrm{p}_{2.3}=0,311 ; \\
\mathrm{p}_{2.4}=0,083 ; \mathrm{p}_{3.4}=0,457\end{array}$ & $\begin{array}{l}\mathrm{p}_{1-2}=1,000 ; \mathrm{p}_{1-3}=1,000 ; \\
\mathrm{p}_{1-4}=0,302 ; \mathrm{p}_{2.3}=1,000 ; \\
\mathrm{p}_{2.4}=0,302 ; \mathrm{p}_{3.4}=0,302\end{array}$ & \\
\hline
\end{tabular}

Так, при грудном соматотипе НГЛЖ наряду с КРЛЖ и ЭГЛЖ встречалась с одинаковой частотой - 33,3\%, лиц с КГЛЖ выявлено не было. При мускульном конституциональном типе чаще, на уровне тенденции, выявлялась КГЛЖ - 37,9\%, в сравнении с НГЛЖ - 27,6\%, КРЛЖ - 24,1\% и ЭГЛЖ - 10,3\%. При брюшном соматотипе чаще, на уровне тенденции, выявлялись лица, имеющие КРЛЖ - 39,1\%, в сравнении с НГЛЖ - 17,4\%, КГЛЖ - 26,1\% и ЭГЛЖ - 17,4\% соответственно. При неопределенном типе конституции НГЛЖ наряду с КРЛЖ и КГЛЖ встречалась с одинаковой частотой - 33,3\%, лиц с ЭГЛЖ выявлено не было.

При сравнении частоты вариантов ремоделирования ЛЖ между группами соматотипов можно отметить, что имеется тенденция к более высо- 
кой частоте КРЛЖ - 50,0\% и ЭГЛЖ $-50,0 \%$ при брюшном соматотипе и высокой частоте КГЛЖ - 61,1\% при мускульном типе.

При изучении частота вариантов ремоделирования ЛЖ у мужчин с АГ различных соматотипов, постоянно проживающих в г. Красноярске (табл. 2) установлено, что при грудном соматотипе КГЛЖ и ЭГЛЖ встречалась с одинаковой частотой $-50 \%$, лиц с НГЛЖ и КРЛЖ при этом типе конституции выявлено не было.

Таблица 2.

Частота встречаемости вариантов ремоделирования левого желудочка у жителей г. Красноярска с АГ, различных соматотипов

\begin{tabular}{|c|c|c|c|c|c|}
\hline \multirow{3}{*}{$\begin{array}{c}\text { Тип ремодели- } \\
\text { рования }\end{array}$} & \multicolumn{4}{|c|}{ Соматотипы } & \multirow{3}{*}{$p$} \\
\hline & 1. Грудной & $\begin{array}{l}\text { 2. Мускуль- } \\
\text { ный }\end{array}$ & 3. Брюшной & $\begin{array}{l}\text { 4.Неопреде- } \\
\text { ленный }\end{array}$ & \\
\hline & абс. (\%) & абс. (\%) & абс. $(\%)$ & абс. (\%) & \\
\hline $\begin{array}{l}\text { 1. Нормальная } \\
\text { геометрия ЛЖ }\end{array}$ & $0(0,0 \%)$ & $6(40,0 \%)$ & $9(60,0 \%)$ & $0(0,0 \%)$ & $\begin{array}{l}\mathrm{p}_{1-2}=\mathbf{0 , 0 2 7} ; \mathrm{p}_{1-3}=\mathbf{0 , 0 2 7} ; \\
\mathrm{p}_{1-4}=1,000 ; \mathrm{p}_{2-3}=0,947 ; \\
\mathrm{p}_{2-4}=\mathbf{0 , 0 2 7} ; \mathrm{p}_{3-4}=\mathbf{0 , 0 2 7}\end{array}$ \\
\hline $\begin{array}{l}\text { 2. Концентри- } \\
\text { ческое РЛЖ }\end{array}$ & $0(0,0 \%)$ & $8(36,4 \%)$ & $10(45,5 \%)$ & $4(18,2 \%)$ & $\begin{array}{l}\mathrm{p}_{1-2}=\mathbf{0 , 0 0 8} ; \mathrm{p}_{1-3}=\mathbf{0 , 0 1 9 ;} \\
\mathrm{p}_{1-4}=\mathbf{0 , 0 3 2} \mathrm{p}_{2-3}=0,586 ; \\
\mathrm{p}_{2-4}=0,536 ; \mathrm{p}_{3-4}=0,845\end{array}$ \\
\hline $\begin{array}{l}\text { 3. Концентри- } \\
\text { ческая ГЛЖ }\end{array}$ & $2(5,9 \%)$ & $13(38,2 \%)$ & $18(52,9 \%)$ & $1(2,9 \%)$ & 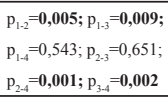 \\
\hline $\begin{array}{l}\text { 4. Эксцентри- } \\
\text { ческая ГЛЖ }\end{array}$ & $2(13,3 \%)$ & $9(60,0 \%)$ & $4(26,7 \%)$ & $0(0,0 \%)$ & $\begin{array}{l}\mathrm{p}_{1-2}=0,072 ; \mathrm{p}_{1-3}=0,877 ; \\
\mathrm{p}_{1-4}=0,143 ; \mathrm{p}_{2-3}=\mathbf{0 , 0 1 2 ;} \\
\mathrm{p}_{2-4}=\mathbf{0 , 0 0 4} ; \mathrm{p}_{3-4}=0,166\end{array}$ \\
\hline$p$ & $\begin{array}{l}\mathrm{p}_{1-2}=1,000 ; \mathrm{p}_{1-3}=0,143 \\
\mathrm{p}_{1-4}=0,143 ; \mathrm{p}_{2-3}=0,143 ; \\
\mathrm{p}_{2-4}=0,143 ; \mathrm{p}_{3-4}=1,000\end{array}$ & $\begin{array}{l}\mathrm{p}_{\mathrm{l}-2}=0,517 ; \mathrm{p}_{1-3}=\mathbf{0 , 0 3 3} \\
\mathrm{p}_{\mathrm{l}-4}=0,340 ; \mathrm{p}_{2-3}=0,131 ; \\
\mathrm{p}_{2-4}=0,757 ; \mathrm{p}_{3-4}=0,228\end{array}$ & $\begin{array}{l}\mathrm{p}_{1-2}=0,787 ; \mathrm{p}_{1-3}=0,026 \\
\mathrm{p}_{1-4}=0,123 ; \mathrm{p}_{2-3}=\mathbf{0 , 0 4 9} \\
\mathrm{p}_{2-4}=0,072 ; \mathrm{p}_{3-4}=\mathbf{0 , 0 0 1}\end{array}$ & $\begin{array}{l}\mathrm{p}_{1-2}=\mathbf{0 , 0 3 2} ; \mathrm{p}_{1-3}=0,309 ; \\
\mathrm{p}_{1-4}=1,000 ; \mathrm{p}_{2-3}=0,142 ; \\
\mathrm{p}_{2-4}=\mathbf{0 , 0 3 2} ; \mathrm{p}_{3-4}=0,309\end{array}$ & \\
\hline
\end{tabular}

При мускульном конституциональном типе чаще, на уровне тенденции, выявлялась КГЛЖ - 36,1\%, в сравнении с НГЛЖ - 16,7\%, КРЛЖ - 22,2\% и ЭГЛЖ - 25,0\%. При брюшном соматотипе чаще, на уровне тенденциии, выявлялись лица, имеющие КГЛЖ - 43,9\%, в сравнении с НГЛЖ - 22,0\%, КРЛЖ $24,4 \%$ и ЭГЛЖ - 9,8\% соответственно. При неопределенном типе конституции КРЛЖ выявлялось у $80 \%$ и КГЛЖ у $20 \%$ обследованных мужчин, лиц с НГЛЖ и КРЛЖ, при данном конституциональном типе, выявлено не было.

При сравнительном анализе частоты вариантов ремоделирования ЛЖ между группами соматотипов мужчин, постоянно проживающих в г. Красноярске, можно отметить, что имеется тенденция к более высокой частоте КРЛЖ - 45,0\% и КГЛЖ - 52,9\% при брюшном соматотипе и высокой частоте ЭГЛЖ - 60,0\% при мускульном типе конституции (табл. 2). 
Резюмируя вышеизложенное следует отметить, что проведенное исследование позволило выявить и количественно охарактеризовать распределение неблагоприятных типов ремоделирования ЛЖ у мужчин, мигрантов Крайнего Севера и лиц, постоянно проживающих в г. Красноярске с АГ, по конституциональным типам. Выявленные конституциональные особенности частоты неблагоприятных типов геометрии ЛЖ у мужчин обследованных групп могут быть использованы для персонифицированной оценки сердечно-сосудистого риска.

\section{Выводы}

Установлено, что неблагоприятные типы геометрии ЛЖ чаще встречаются у лиц с конституциональными типами, характеризующиеся высоким содержание жировой ткани (брюшной соматотип) и мышечной ткани (мускульный соматотип) как среди мужчин мигрантов, так и среди мужчин, постоянно проживающих в г. Красноярске. Выявлены конституциональные особенности частоты неблагоприятных типов геометрии ЛЖ у мужчин обследованных групп. Для мигрантов с АГ характерна высокая частота ЭГЛЖ при брюшном соматотипе и высокая частота КГЛЖ при мускульном, в то время как для постоянно проживающих в г. Красноярске, характерна высокая частота КГЛЖ при брюшном соматотипе и высокая частота ЭГЛЖ при мускульном соматотипе.

\section{Список литературы}

1. Давыдов Е. Л., Ульянова И. О. Медико-социальные аспекты больных артериальной гипертонией в пожилом возрасте // Клиническая геронтология. 2016. Т. 22, № 9-10. С. 24-25.

2. Деревянных Е. В., Яскевич Р. А., Балашова Н. А. Антропометрические особенности и компонентный состав массы тела у мужчин медицинских работников с артериальной гипертонией // Международный журнал прикладных и фундаментальных исследований. 2016. № 6-2. С. 252-256.

3. Деревянных Е. В., Яскевич Р. А., Балашова Н. А. Возрастные особенности приверженности к лечению артериальной гипертонии у мужчин г. Красноярска // Международный журнал прикладных и фундаментальных исследований. 2016. № 6-1. С. 48-52.

4. Деревянных Е. В., Яскевич Р. А., Балашова Н. А., Москаленко О. Л. Распространенность избыточной массы тела среди женщин медицинских работников крупной клинической больницы города Красноярска // В мире научных открытий. 2016. № 7 (79). С. 26-46. 
5. Кандилова В. Н. Ремоделирование сердца и сосудов при артериальной гипертензии: роль сопутствующего ожирения // Клиницист. 2020. Т. 14, № 1-2. С. $62-72$.

6. Кедринская А. Г., Куприенко Н. Б., Образцова Г. И., Леонова И.А. Структурные изменения сердца и антропометрические маркеры ремоделирования миокарда при избыточной массе тела и ожирении у детей // Артериальная гипертензия. 2018. Т. 24, № 5. С.570-580.

7. Клеменков А. С., Фурсова Я. Е., Клеменков С. В. и др. Влияние общих пресных ванн и физических тренировок при разной длительности назначения на физическую работоспособность больных стабильной стенокардией с нарушением ритма // Фундаментальные исследования. 2006. № 3. C. 13 .

8. Коган М. П., Филимонова Е. Э., Сорокин Е. Л., Кривко С. В. Возможности использования типологии морфофункционального строения организма человека в клинических исследованиях // Здравоохранение Дальнего Востока. 2020. № 1 (83). С. 90-94.

9. Козлов Е. В., Яскевич Р. А., Москаленко О. Л., Кочергина К. Н. Антропометрические особенности и компонентный состав массы тела у мужчин с хронической обструктивной болезнью легких в условиях коморбидности // Siberian Journal of Life Sciences and Agriculture. 2019. T. 11. № 4. C. 56-73.

10. Москаленко О. Л. Характеристика свойств темперамента у юношей-студентов разных соматотипов г. Железногорска // В мире научных открытий. 2015. № 8.1 (68). С. 442-449.

11. Никитюк Д. Б., Николенко В. Н., Хайруллин Р. М. и др. Антропометрический метод и клиническая медицина // Журнал анатомии и гистопатологии. 2013. T. 2, № 2. С. 10-14.

12. Поликарпов Л. С., Хамнагадаев И. И., Яскевич Р. А., Деревянных Е. В. Артериальная гипертония (распространенность, профилактика, адаптация и реадаптация к различным экологическим условиям). Красноярск: КрасГMУ, 2010. 289 c.

13. Хаснулин В. В., Воевода М. И., Хаснулин П. В., Артамонова О. Г. Современный взгляд на проблему артериальной гипертензии в приполярных и арктических регионах. Обзор литературы // Экология человека. 2016. №3. C.43-51.

14. Яскевич Р. А., Деревянных Е. В., Балашова Н. А. Использование показателей соматотипирования у мужчин в построении математических моделей прогноза развития артериальной гипертонии // Международный журнал прикладных и фундаментальных исследований. 2015. № 1-1. С. 64-69. 
15. Яскевич Р. А., Повшедная О. Н., Деревянных Е. В. Нарушения ритма сердца у мужчин, жителей Сибири, с артериальной гипертонией различных конституциональных типов // Успехи современного естествознания. 2015. № 3. С. 127-132.

16. Яскевич Р. А., Москаленко О. Л. Антропометрические особенности и компонентный состав массы тела у мужчин мигрантов Крайнего Севера с артериальной гипертонией // В мире научных открытий. 2016. № 10 (82). С. 10-34.

17. Яскевич Р. А. Частота вариантов ремоделирования левого желудочка у больных с артериальной гипертонией различных конституциональных типов // Научное обозрение. Медицинские науки. 2020. № 4. С. 81-87.

18. Artyukhov I. P., Grinshtein Y. I., Petrova M. M. et al. Prevalence of arterial hypertension in the Krasnoyarsk Krai (Siberia, Russia) // BMC Cardiovasc. Disord. 2017. Vol. 17. P. 138.

19. Britton K.A., Massaro J. M., Murabito J. M. et al. Body fat distribution, incident cardiovascular disease, cancer, and all-cause mortality // J. Am. Coll. Cardiol. 2013. Vol. 62, N.10. - P.921-925.

20. Kim N. Y., Hong Y. M., Jung J. W. et al. The relationships of body mass index, waist-to-height ratio, and body fat percentage with blood pressure and its hemodynamic determinants in Korean adolescents: a school-based study // Korean J. Pediatr. 2013. Vol. 56, N 12. P. 526-533.

21. Nichols M., Townsend N., Scarborough P., Rayner M. Cardiovascular disease in Europe: epidemiological update // Eur. Heart J. 2013. Vol.34. P. 3028-3034.

22. Polikarpov L. S., Yaskevich R. A., Derevyannich E. V. et al. Readaptation of patients with arterial hypertension long-term residents of the Far North to new climatic conditions // International Journal of Circumpolar Health. 2012. Vol. 72, S 1. P. 337-339.

23. Selvaraj S., Martinez E. E., Aguilar F. G. et al. Association of central adiposity with adverse cardiac mechanics: findings from the HyperGEN Study // Circ.: Cardiovasc. Imaging. 2016. Vol. 9, N 6. P. e004396.

24. Shurkevich N. P., Vetoshkin A. S., Gapon L. I., Gubin D. G. Structural changes in myocardium and 24-hour blood pressure profile in subjects with arterial hypertension studies during shift work in far north // European Heart Journal. 2018. Vol. 39, S 1. P. 596.

25. Williams B., Mancia G., Spiering W. et al; ESC Scientific Document Group. 2018 ESC/ESH Guidelines for the management of arterial hypertension. The Task Force for the management of arterial hypertension of the European Society of Cardiology (ESC) and the European Society of Hypertension (ESH) // European Heart Journal. 2018. Vol. 39, N 33. P. 3021-104. 


\section{References}

1. Davydov E. L., Ul'yanova I. O. Mediko-sotsial'nye aspekty bol'nykh arterial'noy gipertoniey v pozhilom vozraste [Medico-social aspects of patients with arterial hypertension in old age]. Klinicheskaya gerontologiya [Clinical gerontology]. 2016. V. 22. № 9-10. P. 24-25.

2. Derevyannykh E. V., Yaskevich R. A., Balashova N. A. Antropometricheskie osobennosti i komponentnyy sostav massy tela u muzhchin meditsinskikh rabotnikov s arterial'noy gipertoniey [Anthropometric characteristics and component composition of body weight in male medical workers with arterial hypertension]. Mezhdunarodnyy zhurnal prikladnykh i fundamental'nykh issledovaniy [International Journal of Applied and Fundamental Research]. 2016. № 6-2. P. 252-256.

3. Derevyannykh E. V., Yaskevich R. A., Balashova N. A. Vozrastnye osobennosti priverzhennosti k lecheniyu arterial'noy gipertonii u muzhchin g. Krasnoyarska [Age characteristics of adherence to the treatment of arterial hypertension in men in Krasnoyarsk]. Mezhdunarodnyy zhurnal prikladnykh i fundamental'nykh issledovaniy [International Journal of Applied and Fundamental Research]. 2016. № 6-1. P. 48-52.

4. Derevyannykh E. V., Yaskevich R. A., Balashova N. A., Moskalenko O. L. Rasprostranennost' izbytochnoy massy tela sredi zhenshchin meditsinskikh rabotnikov krupnoy klinicheskoy bol'nitsy goroda Krasnoyarska [Prevalence of overweight among women medical workers of a large clinical hospital in Krasnoyarsk]. $V$ mire nauchnykh otkrytiy [In the world of scientific discoveries]. 2016. № 7(79). P. 26-46.

5. Kandilova V. N. Remodelirovanie serdtsa i sosudov pri arterial'noy gipertenzii: rol' soputstvuyushchego ozhireniya [Remodeling of the heart and blood vessels in arterial hypertension: the role of concomitant obesity]. Klinitsist [Clinician]. 2020. V. 14. № 1-2. P. 62-72.

6. Kedrinskaya A. G., Kuprienko N. B., Obraztsova G. I., Leonova I.A. Strukturnye izmeneniya serdtsa i antropometricheskie markery remodelirovaniya miokarda pri izbytochnoy masse tela i ozhirenii u detey [Structural changes in the heart and anthropometric markers of myocardial remodeling in overweight and obesity in children]. Arterial'naya gipertenziya [Arterial hypertension]. 2018. V. 24. № 5. P.570-580.

7. Klemenkov A. S., Fursova Ya. E., Klemenkov S. V. i dr. Vliyanie obshchikh presnykh vann i fizicheskikh trenirovok pri raznoy dlitel'nosti naznacheniya na fizicheskuyu rabotosposobnost' bol'nykh stabil'noy stenokardiey s narusheniem ritma [Influence of general fresh baths and physical training with different duration of appointment on the physical performance of patients with stable angina pectoris with rhythm disturbances]. Fundamental'nye issledovaniya [Fundamental research]. 2006. № 3. P. 13. 
8. Kogan M. P., Filimonova E. E., Sorokin E. L., Krivko S. V. Vozmozhnosti ispol'zovaniya tipologii morfofunktsional'nogo stroeniya organizma cheloveka v klinicheskikh issledovaniyakh [Possibilities of using the typology of the morphofunctional structure of the human body in clinical research]. Zdravookhranenie Dal'nego Vostoka [Healthcare of the Far East]. 2020. №1(83). P. 90-94.

9. Kozlov E. V., Yaskevich R. A., Moskalenko O. L., Kochergina K. N. Antropometricheskie osobennosti i komponentnyy sostav massy tela u muzhchin s khronicheskoy obstruktivnoy bolezn'yu legkikh v usloviyakh komorbidnosti [Anthropometric features and component composition of body weight in men with chronic obstructive pulmonary disease in conditions of comorbidity]. Siberian Journal of Life Sciences and Agriculture. 2019. V. 11. № 4. P. 56-73.

10. Moskalenko O. L. Kharakteristika svoystv temperamenta u yunoshey-studentov raznykh somatotipov g. Zheleznogorska [Characteristics of the properties of temperament in young men-students of different somatotypes of the city of Zheleznogorsk]. V mire nauchnykh otkrytiy [In the world of scientific discoveries]. 2015. № 8.1(68). P. 442-449.

11. Nikityuk D. B., Nikolenko V. N., Khayrullin R. M. i dr. Antropometricheskiy metod i klinicheskaya meditsina [Anthropometric method and clinical medicine]. Zhurnal anatomii i gistopatologii [Journal of Anatomy and Histopathology]. 2013. V. 2. № 2. P. 10-14.

12. Polikarpov L. S., Khamnagadaev I. I., Yaskevich R. A., Derevyannykh E. V. Arterial'naya gipertoniya (rasprostranennost', profilaktika, adaptatsiya i readaptatsiya $k$ razlichnym ekologicheskim usloviyam) [Arterial hypertension (prevalence, prevention, adaptation and readaptation to various environmental conditions)]. Krasnoyarsk: KrasGMU. 2010. 289 p.

13. Khasnulin V. V., Voevoda M. I., Khasnulin P. V., Artamonova O. G. Sovremennyy vzglyad na problemu arterial'noy gipertenzii v pripolyarnykh i arkticheskikh regionakh. Obzor literatury [Modern view of the problem of arterial hypertension in the circumpolar and arctic regions. Literature review]. Ekologiya cheloveka [Human Ecology]. 2016. №3. P.43-51.

14. Yaskevich R. A., Derevyannykh E. V., Balashova N. A. Ispol'zovanie pokazateley somatotipirovaniya u muzhchin $\mathrm{v}$ postroenii matematicheskikh modeley prognoza razvitiya arterial'noy gipertonii [The use of somatotyping indicators in men in the construction of mathematical models for predicting the development of arterial hypertension]. Mezhdunarodnyy zhurnal prikladnykh i fundamental'nykh issledovaniy [International Journal of Applied and Fundamental Research]. 2015. № 1-1. P. 64-69.

15. Yaskevich R. A., Povshednaya O. N., Derevyannykh E. V. Narusheniya ritma serdtsa u muzhchin, zhiteley Sibiri, s arterial'noy gipertoniey razlichnykh konstitut- 
sional'nykh tipov [Heart rhythm disturbances in men, inhabitants of Siberia, with arterial hypertension of various constitutional types]. Uspekhi sovremennogo estestvoznaniya [Successes of modern natural science]. 2015. № 3. P. 127-132.

16. Yaskevich R. A., Moskalenko O. L. Antropometricheskie osobennosti i komponentnyy sostav massy tela u muzhchin migrantov Kraynego Severa s arterial'noy gipertoniey [Anthropometric characteristics and component composition of body weight in male migrants of the Far North with arterial hypertension]. V mire nauchnykh otkrytiy [In the world of scientific discoveries]. 2016. № 10 (82). P. 10-34.

17. Yaskevich R.A. Chastota variantov remodelirovaniya levogo zheludochka $u$ bol'nykh s arterial'noy gipertoniey razlichnykh konstitutsional'nykh tipov [Frequency of variants of left ventricular remodeling in patients with arterial hypertension of various constitutional types]. Nauchnoe obozrenie. Meditsinskie nauki [Scientific Review. Medical sciences]. 2020. № 4. P. 81-87.

18. Artyukhov I. P., Grinshtein Y. I., Petrova M. M. et al. Prevalence of arterial hypertension in the Krasnoyarsk Krai (Siberia, Russia). BMC Cardiovasc. Disord. 2017. Vol. 17. P. 138.

19. Britton K.A., Massaro J. M., Murabito J. M. et al. Body fat distribution, incident cardiovascular disease, cancer, and all-cause mortality. J. Am. Coll. Cardiol. 2013. Vol. 62. N.10. P.921-925.

20. Kim N. Y., Hong Y. M., Jung J. W. et al. The relationships of body mass index, waist-to-height ratio, and body fat percentage with blood pressure and its hemodynamic determinants in Korean adolescents: a school-based study. Korean J. Pediatr. 2013. Vol. 56. N12. P. 526-533.

21. Nichols M., Townsend N., Scarborough P., Rayner M. Cardiovascular disease in Europe: epidemiological update. Eur. Heart J. 2013. Vol.34. P. 3028-3034.

22. Polikarpov L.S., Yaskevich R.A., Derevyannich E.V. et al. Readaptation of patients with arterial hypertension long-term residents of the Far North to new climatic conditions. International Journal of Circumpolar Health. 2012. Vol. 72. S 1. P. 337-339.

23. Selvaraj S., Martinez E. E., Aguilar F. G. et al. Association of central adiposity with adverse cardiac mechanics: findings from the HyperGEN Study. Circ.: Cardiovasc. Imaging. 2016. Vol. 9. N 6. P. e004396.

24. Shurkevich N. P., Vetoshkin A. S., Gapon L. I., Gubin D. G. Structural changes in myocardium and 24-hour blood pressure profile in subjects with arterial hypertension studies during shift work in far north. European Heart Journal. 2018. Vol. 39. S 1. P. 596.

25. Williams B., Mancia G., Spiering W. et al; ESC Scientific Document Group. $2018 \mathrm{ESC} / \mathrm{ESH}$ Guidelines for the management of arterial hypertension. The Task Force for the management of arterial hypertension of the European So- 
ciety of Cardiology (ESC) and the European Society of Hypertension (ESH). European Heart Journal. 2018. Vol. 39. N 33. P. 3021-104.

\section{ДАННЫЕ ОБ АВТОРАХ}

Яскевич Роман Анатольевич, доцент кафедры пропедевтики внутренних болезней и терапии, ведущий научный сотрудник группы патологии сердечно-сосудистой системы, кандидат медицинских наук, доцент Федеральное государственное бюджетное научное учреждение «Научно-исследовательский институт медииинских проблем Севера»; ФГБОУ ВО КрасГМУ им. проф. В.Ф. Войно-Ясенечкого Минздрава России

ул. Партизана Железняка, 32, г. Красноярск, 660022, Российская Федерачия; ул. Партизана Железняка, 1а, г. Красноярск, 660022, Российская Федерация cardio@impn.ru

Москаленко Ольга Леонидовна, старший научный сотрудник, кандидат биологических наук Федеральное государственное бюджетное научное учреждение «Научно-исследовательский институт медииинских проблем Севера» ул. Партизана Железняка, 32, г. Красноярск, 660022, Российская Федераиия gre-ll@mail.ru

\section{DATA ABOUT THE AUTHORS}

Yaskevich Roman Anatolyevich, Associate Professor at Department of Propedeutics of Internal Diseases and Therapy, Leading Researcher of the Group Pathology of the Cardiovascular System, Candidate of Medical Science, Docent

Scientific Research Institute of medical problems of the North; Krasnoyarsk State Medical University named after Professor V.F. Voino-Yasenetzkiy 3g, P. Zheleznyaka St., Krasnoyarsk, 660022, Russian Federation; 1a, P. Zheleznyaka St., Krasnoyarsk, 660022, Russian Federation cardio@impn.ru

Moskalenko Olga Leonidovna, Senior Researcher, Candidate of Biological Sciences

Scientific Research Institute of medical problems of the North 3g, P. Zheleznyaka St., Krasnoyarsk, 660022, Russian Federation gre-ll@mail.ru 